\title{
Tempering Influence on Residual Stresses and Mechanical Properties of AISI 4340 Steel
}

\author{
Marcel Souza ( $\nabla$ marcelfreitas@id.uff.br) \\ Luana Ferreira Serrão \\ Universidade Federal Fluminense \\ Juan Manuel Pardal \\ Universidade Federal Fluminense \\ Sérgio Souto Maior Tavares \\ Universidade Federal Fluminense \\ Maria Cindra Fonseca \\ Universidade Federal Fluminense
}

Universidade Federal Fluminense https://orcid.org/0000-0002-2489-7399

\section{Research Article}

Keywords: AISI 4340 steel, heat treatments, mechanical properties, residual stresses, $\mathrm{X}$ ray diffraction, magnetic Barkhausen noise

Posted Date: November 9th, 2021

DOI: https://doi.org/10.21203/rs.3.rs-1051431/v1

License: (c) (i) This work is licensed under a Creative Commons Attribution 4.0 International License. Read Full License

Version of Record: A version of this preprint was published at The International Journal of Advanced Manufacturing Technology on February 10th, 2022. See the published version at https://doi.org/10.1007/s00170-022-08880-3. 


\title{
Tempering influence on residual stresses and mechanical properties of AISI 4340 steel
}

\author{
Marcel Freitas de Souza, Luana Ferreira Serrão, Juan Manuel Pardal, Sérgio Souto Maior \\ Tavares, Maria Cindra Fonseca* \\ Department of Mechanical Engineering, School of Engineering/PGMEC, Universidade \\ Federal Fluminense - Rua Passo da Patria, 156 - CEP 24210-240, Niteroi, RJ, Brazil. \\ *E-mail: mariacindra@id.uff.br
}

\begin{abstract}
The present work evaluated the tempering temperature influence on microstructure, mechanical properties and residual stresses of AISI 4340 steel. The residual stresses were measured by X-ray diffraction (XRD) by the $\sin ^{2} \psi$ method and compared to magnetic Barkhausen noise $(\mathrm{MBN})$. The residual stresses exhibited high tensile values after quenching, but a small relief was observed in tempering treatments at $300^{\circ} \mathrm{C}$ and $400^{\circ} \mathrm{C}$, which also presented a hardness decrease compared to the as-quenched condition. XRD and MBN analyses indicated that residual stresses became compressive in tempering performed between $500^{\circ} \mathrm{C}$ and $650^{\circ} \mathrm{C}$. Therefore, compressive residual stresses combined with appropriate hardness and toughness values (35 $\mathrm{HRC}$ and $33 \mathrm{~J}$ ) obtained from $500^{\circ} \mathrm{C}$ tempering temperature can be used to improve the mechanical properties of AISI 4340 steel components. Additionally, a mathematical model was established to estimate the tempered martensite hardness for different tempering temperature conditions. This model showed high accuracy $\left(\mathrm{R}^{2}=0.99\right)$ for a holding time of 90 minutes.
\end{abstract}

Keywords: AISI 4340 steel; heat treatments; mechanical properties; residual stresses; X-ray diffraction; magnetic Barkhausen noise. 


\section{Introduction}

The AISI 4340 steel is employed in quenched and tempered conditions, however, is susceptible to embrittlement phenomena when tempered between 300 and $400^{\circ} \mathrm{C}$. This problem has been investigated by several researchers, who have evaluated changes in microstructure and mechanical properties at different tempering temperatures [1-3].

Tempering can be used as a stress relief process, ensuring reduction or even absence of tensile residual stresses, which have a deleterious effect on fatigue life. Despite the wide industrial use of AISI 4340 steel and in-depth study of the mechanical behaviour of this material, there is little information in the literature regarding the influence of heat treatment parameters on residual stresses.

Incorrect selection of heat treatment parameters leads to significant changes in material properties and hence performance in service. Therefore, it is important to evaluate nondestructive and low-cost residual stresses techniques, such as magnetic Barkhausen noise (MBN), which can be implemented in production lines and provide reliable results, highlighting $\mathrm{X}$-ray diffraction technique (XRD) in these conditions [4-8].

The present work evaluated changes in mechanical properties, microstructure, residual stresses and MBN for AISI 4340 steel at different tempering temperatures.

\section{Materials and Experimental Techniques}

The AISI 4340 steel studied was obtained from a disc of $10.5 \mathrm{~mm}$ thickness, cut from a forged and normalized bar of $\varnothing 228.6 \mathrm{~mm}$. Chemical composition and mechanical properties

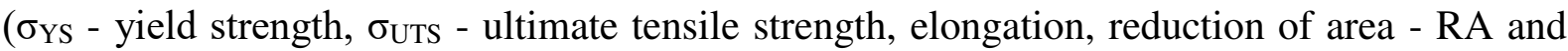
Rockwell hardness - HRC), according to the manufacturer, are shown in Table 1 and Table 2, respectively.

Table 1. Chemical composition of AISI 4340 (\% weight).

\begin{tabular}{c|c|c|c|c|c|c|c|c|c|c}
\hline & $\mathrm{C}$ & $\mathrm{Mn}$ & $\mathrm{Si}$ & $\begin{array}{c}\mathrm{P} \\
(\max )\end{array}$ & $\begin{array}{c}\mathrm{S} \\
(\max )\end{array}$ & $\mathrm{Cr}$ & $\mathrm{Ni}$ & $\mathrm{Mo}$ & $\mathrm{Al}$ & $\mathrm{Cu}$ \\
\hline Manufacturer & 0.40 & 0.73 & 0.28 & 0.01 & 0.02 & 0.78 & 1.73 & 0.21 & 0.02 & 0.11 \\
\hline \multirow{2}{*}{ SAE 4340 } & $\begin{array}{c}0.38 \\
-\end{array}$ & $\begin{array}{c}0.60 \\
-\end{array}$ & $\begin{array}{c}0.15 \\
-\end{array}$ & 0.04 & 0.04 & $\begin{array}{c}0.70 \\
-\end{array}$ & $\begin{array}{c}1.65 \\
-\end{array}$ & $\begin{array}{c}0.20 \\
-\end{array}$ & - & - \\
\hline
\end{tabular}


Table 2. Mechanical properties of AISI 4340.

\begin{tabular}{c|c|c|c|c}
\hline$\sigma_{\text {YS }}(\mathrm{MPa})$ & $\sigma_{\text {UTS }}(\mathrm{MPa})$ & Elongation $(\%)$ & RA $(\%)$ & Rockwell Hardness (HRC) \\
\hline 765 & 960 & 14.8 & 39.5 & 32 \\
\hline
\end{tabular}

Two different types of samples were made from the AISI 4340 steel. One type had Charpy dimensions and was used to assess residual stresses by XRD, MBN and absorbed energy (AE) in the Charpy impact test, which also enabled fractured surface analysis. The other type, called reduced sample, was manufactured to analyse microstructure and Rockwell C hardness (HRC).

Quenching treatment was carried out in a tubular furnace with a controlled argon inert gas atmosphere to avoid decarburizing. The samples were placed in a furnace at $660^{\circ} \mathrm{C}$, which was heated gradually until the soaking temperature of $860^{\circ} \mathrm{C}$. After $60 \mathrm{~min}$ soaking time, the samples were removed and dipped in oil. A quenched sample of each type was selected for tempering, which was carried out using five different temperatures, $300^{\circ} \mathrm{C}, 400^{\circ} \mathrm{C}, 500^{\circ} \mathrm{C}$, $600^{\circ} \mathrm{C}$ and $650^{\circ} \mathrm{C}$, for $90 \mathrm{~min}$ and later air-cooled.

Rockwell $\mathrm{C}$ hardness test was performed in as-received condition and after tempering treatment. Metallographic samples were etched with $2 \%$ Nital for $10 \mathrm{~s}$.

Charpy impact test was performed at room temperature using a universal impact machine with $300 \mathrm{~J}$ capacity and $0.5 \mathrm{~J}$ accuracy and broken Charpy specimens were observed through a stereo microscope.

Fracture surfaces were characterized by scanning electron microscope (SEM) and energy dispersive spectroscopy (EDS) was used to determine the chemical composition of the phases and inclusions in fracture surfaces.

Residual stresses of as-received and heat-treated conditions were measured by XRD using $\sin ^{2} \psi$ method, $\mathrm{CrK} \alpha$ radiation and diffracting the plane $\{211\}$ in the longitudinal direction (LRS), coincident with the largest length direction, and also in the transverse direction (TRS).

MBN used a sinusoidal magnetic field with $125 \mathrm{~Hz}$ frequency, $4.8 \mathrm{Vpp}$ excitation magnetization amplitude and $0.6 \mathrm{~V}$ gain for signal amplification in the longitudinal (LMBN) and transverse (TMBN) directions.

The tests performed in this work are shown in Figure 1. 


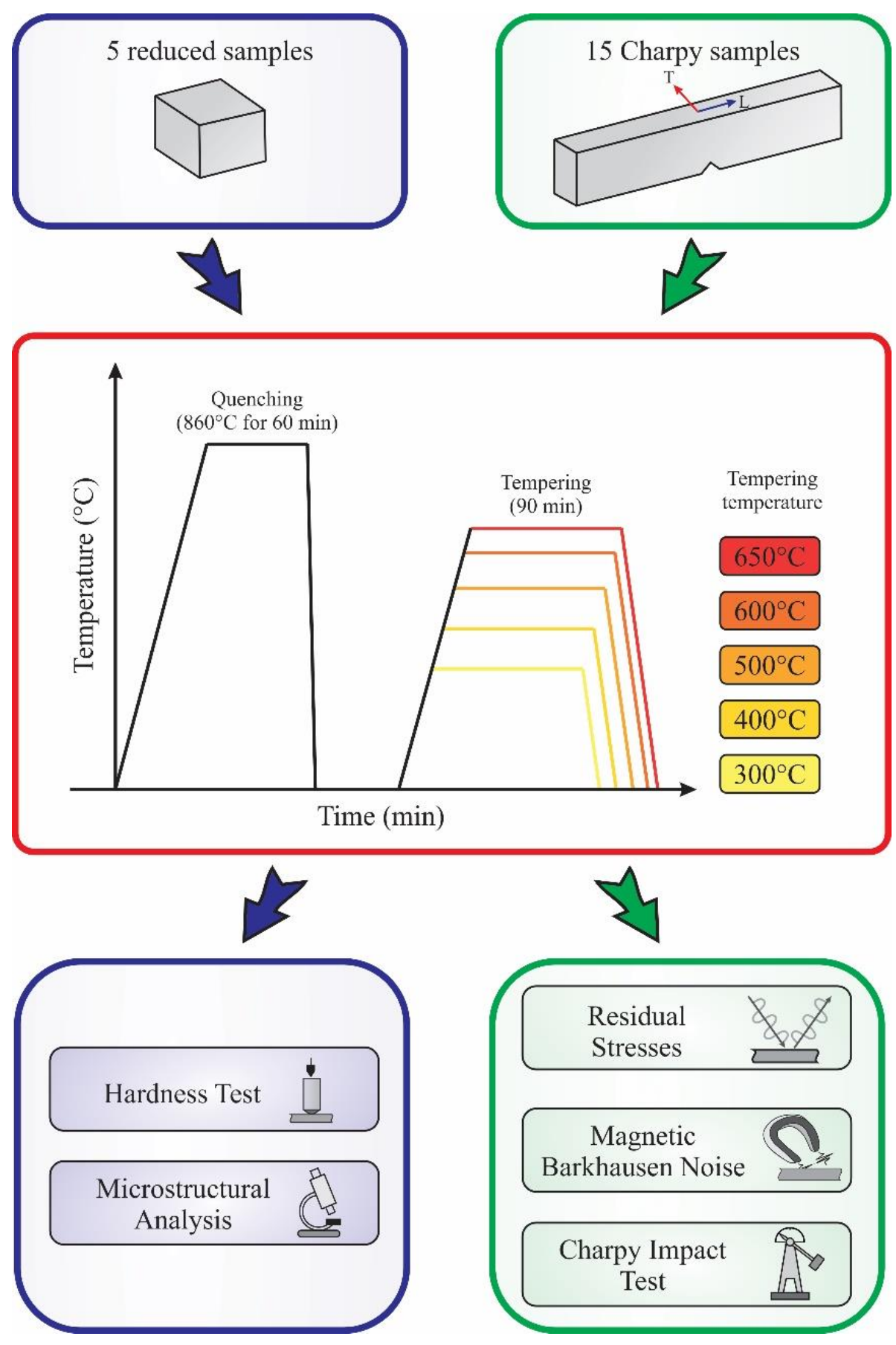

Figure 1. Flowchart with heat treatment parameters and tests performed in this experiment.

\section{Results and Discussions}

Figure 2 presents the results of residual stresses, magnetic Barkhausen noise, Charpy impact toughness test and Rockwell hardness test. 


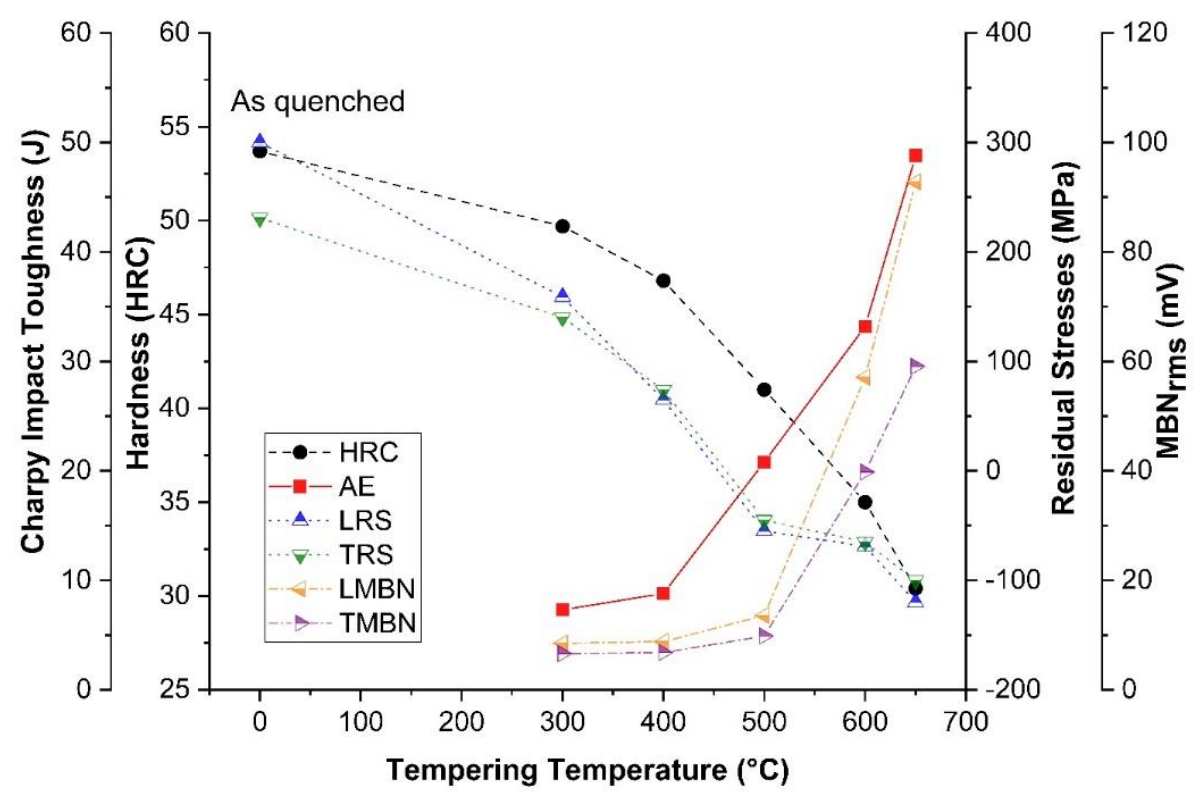

Figure 2. Mechanical properties, residual stresses and MBN vs. tempering temperature.

Oil quenching provided higher hardness values than as-received material, which presented $30 \pm 1 \mathrm{HRC}$. The tempering at $300^{\circ} \mathrm{C}$ led to a reduction of less than $8 \%$ in the hardness concerning quenched condition and, therefore, low tempering does not significantly change hardness [9].

Hardness gradually decreased with increasing tempering temperature, as also verified by Kashefi et al. [4], who affirmed that tempering temperature is significant in hardness reduction due to softening of martensitic matrix by carbon rejection. Manokaran et al. [10] reported hardness values similar to that observed in the present research considering different tempering temperature for AISI 4340. In this way, higher tempering temperatures provide sufficient mobility for the substitutional alloying elements to cause cementite growth, resulting in a continuous decrease in strength during tempering [11].

The absorbed energies of the specimens tempered at $300^{\circ} \mathrm{C}$ and $400^{\circ} \mathrm{C}$ were considerably low and below that found by Kwon et al. [2] and Chi et al. [3]. Temper embrittlement occurs, according to Clarke et al. [1], with tempering in $200^{\circ} \mathrm{C}$ to $400^{\circ} \mathrm{C}$ probably due to the formation of intra-lath cementite from retained austenite. For this reason, this temperature range is critical, making it recommendable to use temperatures between $150^{\circ} \mathrm{C}$ and $200^{\circ} \mathrm{C}$ for low tempering treatment to obtain an adequate combination of strength and ductility.

For tempering temperatures above $500^{\circ} \mathrm{C}$, the absorbed energy increased considerably and, therefore, a sharp growth of energy absorbed with increased tempering temperature was verified, which is consistent with Jiang et al. [8]. 
Residual stresses in the as-received condition indicated a mean of $86 \mathrm{MPa}$ in longitudinal (LRS) direction and -220 MPa in transverse (TRS) direction. The magnitude and nature of residual stresses are influenced by heat treatment and machining process, and probably the thermal effects of electrical discharge machining prevailed in the longitudinal direction, generating tensile residual stresses [12].

Residual stresses after quenching were close to $300 \mathrm{MPa}$ in the longitudinal direction and $230 \mathrm{MPa}$ in the transverse direction. Tensile residual stresses are undesirable since they can decrease the fatigue life by promoting nucleation and propagation of surface cracks [13].

In tempering carried out above $500^{\circ} \mathrm{C}$, the stress relief was even more significant and provided the inversion of stresses nature, generating compressive residual stresses in both directions. Thus, the increase in the tempering temperature made the treatment more efficient in terms of reducing the tensile residual stresses resulting from the quenching.

The hardness profile is similar to the residual stresses behaviour, since both were inversely proportional to tempering temperature increase and, therefore, opposite to the Charpy impact toughness result.

The magnetic Barkhausen noise measured after tempering between $300^{\circ} \mathrm{C}$ and $500^{\circ} \mathrm{C}$ were low and without a significant difference concerning the direction. Tempering performed above $500^{\circ} \mathrm{C}$ increased $\mathrm{MBN}$ and this behaviour corresponds to a compressive residual stresses state. The increase in tempering temperature caused the decrease of anchor points of the magnetic domain and, thus, increasing MBN. Davut and Gür [5] state that with increasing tempering temperature for low alloy steel, MBN also rises due to the greater amount of the domain wall displacement because of the microstructural change of the tempered martensite, which becomes softer.

Residual stresses and microstructure changes affect MBN, since significant changes can be observed during martensite transformation. Higher tempering temperature influences the precipitated carbides sizes, allowing dislocations to move more easily, causing a sharp decrease in hardness and a MBN increase. As described by Moorthy et al. [6], there is an increment in MBN magnitude with hardness reduction, because the domain wall displacement would be facilitated with microstructure softening.

Therefore, MBN can be applied to reduce inspection costs in production lines, using a faster and cheaper technique, avoiding destructive tests and ensuring that all samples could be quickly inspected. In ultra-high strength alloy steels, such as AISI 4340, the heat treatment in the range of $300-400^{\circ} \mathrm{C}$ provides an evident reduction in mechanical properties and tensile residual stresses, and this behaviour can be predicted using the MBN technique [7]. 
The mathematical model proposed by Hassan and Jabbar [14] can estimate the hardness of 4340 steel submitted to quenching and tempering treatments. The parameter of tempering (PT) considers that martensite softening is a phenomenon of diffusion controlled throughout the tempering of steels. The PT is a function of tempering temperature, $\mathrm{T}$ in Kelvin, and holding temperature, $\mathrm{t}$ in hours, according to Equation (1) given by Hollomon and Jaffe [15].

$$
P T=T \cdot[\log (t)+G]
$$

Where $\mathrm{G}$ is a constant, being equal to 10.3 for AISI 4340 [16].

Another equation for PT, according to Equation (2), involves the parameters of the alloy elements of the material [14].

$$
P T=T \cdot\left[\log (T)+\left(H_{0}+\sum_{i} H_{i} X_{i}\right)\right]
$$

Where $H_{i}$ is the constant for the alloying element, $X_{i}$ is the mass amount $\%$ of the alloying element, $H_{0}$ is a constant for tempered pure iron, as shown in Table 3.

Table 3. Equation parameters for alloying effect according to Kang and Lee [16].

\begin{tabular}{l|c|c|c|c|c|c|c}
\hline Parameter & $H_{0}$ & $H_{C}$ & $H_{M n}$ & $H_{S i}$ & $H_{N i}$ & $H_{C r}$ & $H_{M o}$ \\
\hline Value & 17.396 & -6.661 & -1.604 & -3.412 & -0.248 & -1.112 & -4.355 \\
\hline
\end{tabular}

Equation (3) describes the hardness of tempered martensite (HTM) in Vickers (HV) with the implementation of the exponential function factor correction, as performed by Hassan and Jabbar [14] in the original methodology proposed by Kang and Lee [16]. This exponential function factor correction was based on the values described in Figure 3 using the conversion of Rockwell hardness into Vickers hardness according to ASTM E140 [17].

$$
H T M=\left(1542.9-\frac{25.3}{X_{C}}\right) \cdot \exp \left(-1.64 \times 10^{-4} \cdot P T\right)
$$

A correlation factor was implemented in Equation (3) to obtain a better fit of the data. This correction factor expressed in Equation (4) is related specifically to a holding time of 1.5 hours.

$$
\text { Factor of correlation }=[85.5 \cdot \ln (T)-564]
$$

Equation (5) can be written by adding the factor of correlation to Equation (3). 


$$
H T M=\left[\left(1542.9-\frac{25.3}{X_{C}}\right) \cdot \exp \left(-1.64 \times 10^{-4} \cdot P T\right)\right]+[85.5 \cdot \ln (T)-564]
$$

Using the methodology developed by Hassan and Jabbar [14] the value of HTM can be expressed using the values of PT expressed in Equations 1 and 2.

$$
\begin{aligned}
H T M=0,5 \cdot\{ & \left(1542.9-\frac{25.3}{X_{C}}\right) \\
& \left.\cdot\left[\exp \left(-1.64 \times 10^{-4} \cdot P T 1\right)+\exp \left(-1.64 \times 10^{-4} \cdot P T 2\right)\right]\right\} \\
& +[85.5 \cdot \ln (T)-564]
\end{aligned}
$$

Where PT1 and PT2 are tempering parameters that were calculated from Equations (1) and (2), respectively.

Figure 3 shows the variation of measured and calculated hardness for a holding time of 1.5 hours with high accuracy $\left(\mathrm{R}^{2}=0.99\right)$.

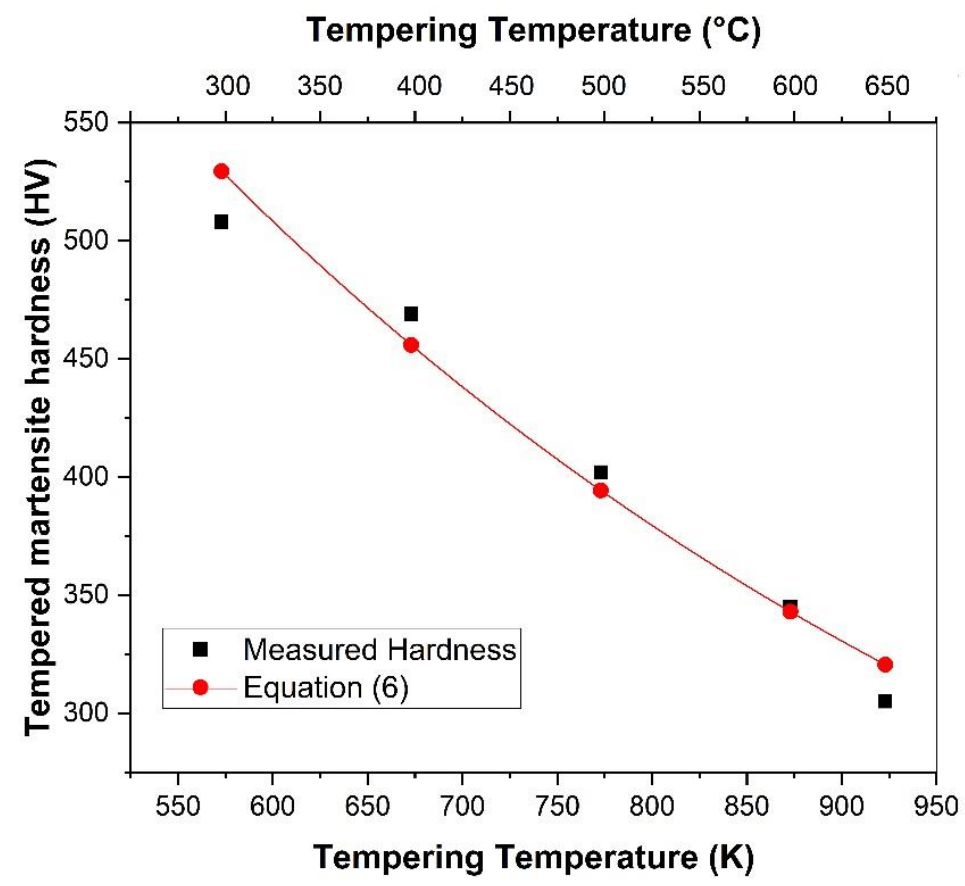

Figure 3. Variation of measured and calculated hardness for a holding time of $1.5 \mathrm{~h}$.

The present research provided a specific model for 1.5 hours and thus complemented the research of Hassan and Jabbar [14], who developed mathematical models for 2 and 48 hours of holding time.

Figure 4 shows the microstructure of quenched and tempered samples. 


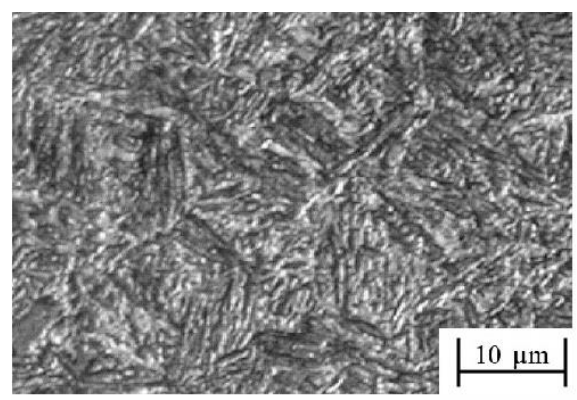

(a)

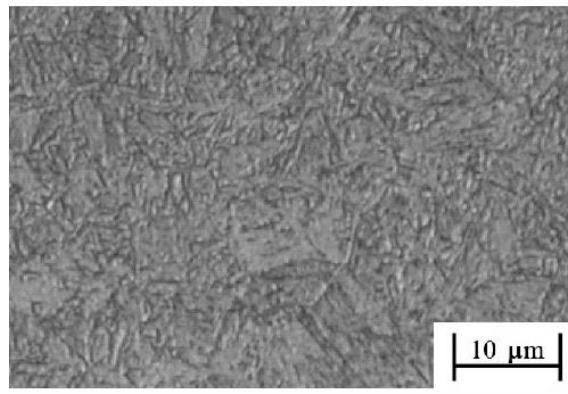

(c)

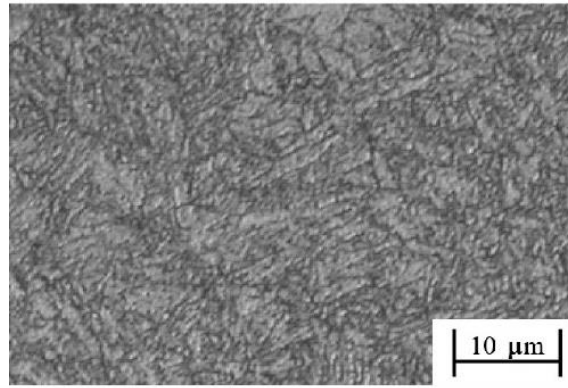

(e)

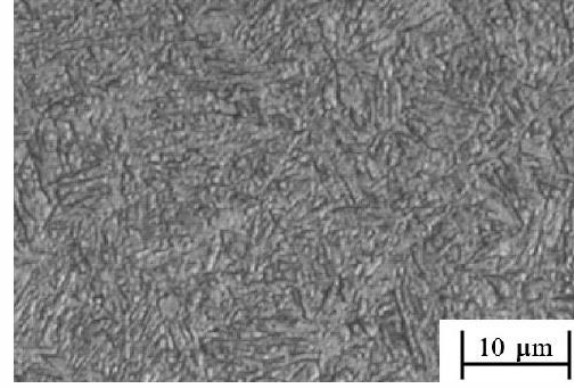

(b)

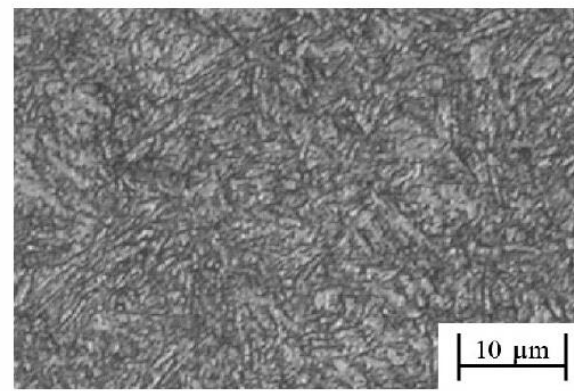

(d)

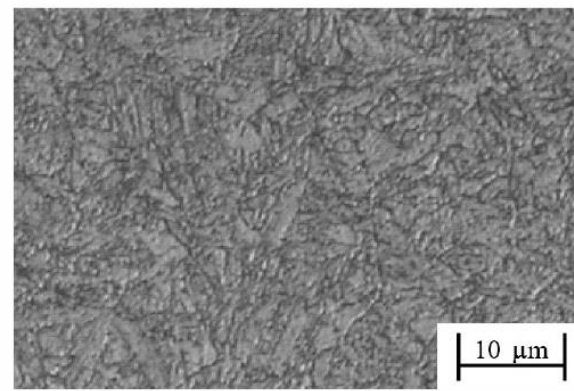

(f)

Figure 4. (a) Microstructure after quenching. Microstructure of tempered sample at: (b) $300^{\circ} \mathrm{C}$, (c) $400^{\circ} \mathrm{C}$, (d) $500^{\circ} \mathrm{C}$, (e) $600^{\circ} \mathrm{C}$ and (f) $650^{\circ} \mathrm{C}$.

Quenching generated, as observed in Figure 4(a), thin martensite laths, which were responsible for the high hardness of this sample. These laths are characteristic of martensite of low alloy steels, which are formed by a diffusionless shear mechanism when austenite is cooled rapidly to room temperature $[11,18]$.

Tempering at $300^{\circ} \mathrm{C}$ promoted low-temperature-tempered martensite formation, as shown in Figure 4(b), not causing significant changes concerning hardness, due to the presence of fine carbides of $\mathrm{Fe}_{2,4} \mathrm{C}$, called $\varepsilon$-phase. This result is consistent with Clarke et al. [1], who also verified carbides after conventional quenching and tempering at $300^{\circ} \mathrm{C}$ for 1 hour.

Tempering at $400^{\circ} \mathrm{C}$, as evidenced in Figure $4(\mathrm{c})$, generated a microstructure similar to Figure 4(b), however, there was a noticeable change in the morphology of the martensite laths with the presence of larger laths. 
Diffusion reactions occur more easily with increasing tempering temperature and, thus, there was a trend towards the formation of more stable carbides, such as $\mathrm{Fe}_{3} \mathrm{C}, \mathrm{M}_{7} \mathrm{C}_{3}$ and $\mathrm{M}_{23} \mathrm{C}_{6}$, providing martensite with less hardness, as observed in Figure 4(d).

For tempering temperatures at $600^{\circ} \mathrm{C}$, diffusional reactions are even more intense when compared to previous conditions. Thus, in addition to the formation of more thermodynamically stable carbides, their growth and coalescence can also occur. Additionally, in this tempering condition, based on the $\mathrm{Fe}-\mathrm{Fe}_{3} \mathrm{C}$ diagram, the temperature is close to the critical temperature $\mathrm{A}_{1}$, favouring the formation of ferrite in the microstructure. In Figure 4(e), coarser morphological aspects of quenched martensite were observed with signs of precipitation of ferrite in the microstructure, which, combined, with the formation of more stable and coarser carbides, led to a decrease in hardness.

The sample tempered at $650^{\circ} \mathrm{C}$ showed characteristics of martensite quenched at high temperatures, highlighting the formation of a microstructure of ferrite and coarse carbides, as evidenced in Figure 4(f). As expected, the hardness suffered a decrease in relation to the tempering condition at $600^{\circ} \mathrm{C}$ and the values were very close to those of the material in the as-received condition.

Fracture surfaces using a stereo microscope with low magnifications are shown in Figure 5. 


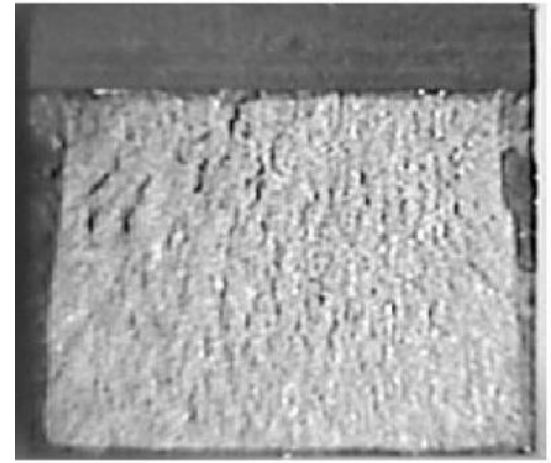

(a)

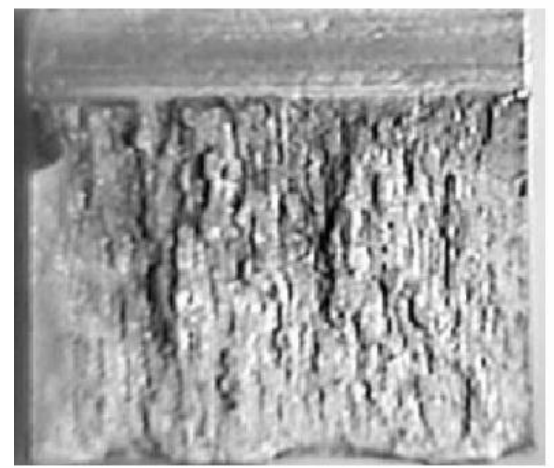

(c)

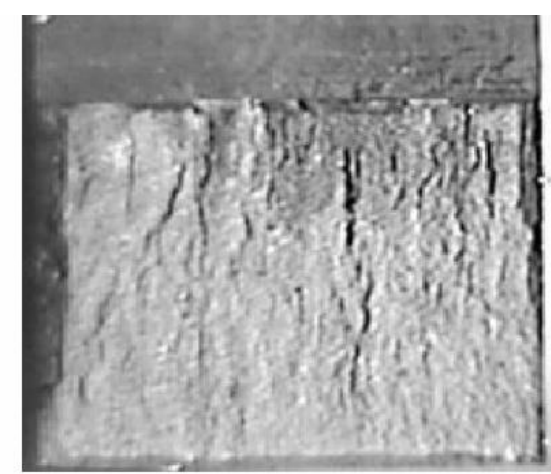

(b)

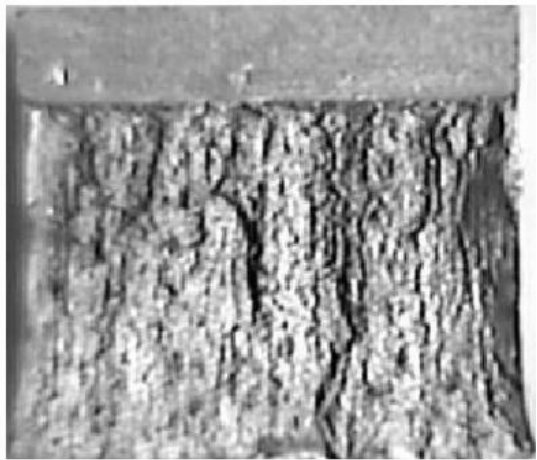

(d)

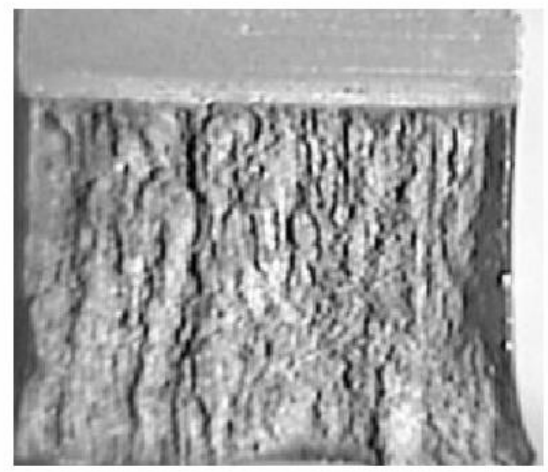

(e)

Figure 5. Fracture surfaces of tempered sample at: (a) $300^{\circ} \mathrm{C}$, (b) $400^{\circ} \mathrm{C}$, (c) $500^{\circ} \mathrm{C}$, (d) $600^{\circ} \mathrm{C}$ and (e) $650^{\circ} \mathrm{C}$.

Figure 5(a) and Figure 5(b) presented brittle fracture surfaces with a low level of plastic deformation, which agrees with the low energy impact test verified in Figure 2. The fracture occurred due to the cleavage mechanism, quite common for this type of fracture and characteristic of samples susceptible to tempering embrittlement phenomena.

Fracture surfaces showed for Figures 5(c), (d) and (e) presented ductile characteristics with a dull appearance and clear signs of plastic deformation with lateral expansion.

Figure 6 shows the microstructures obtained by scanning electron microscope (SEM), in the mode of secondary electrons (SE), for different tempering temperatures. 


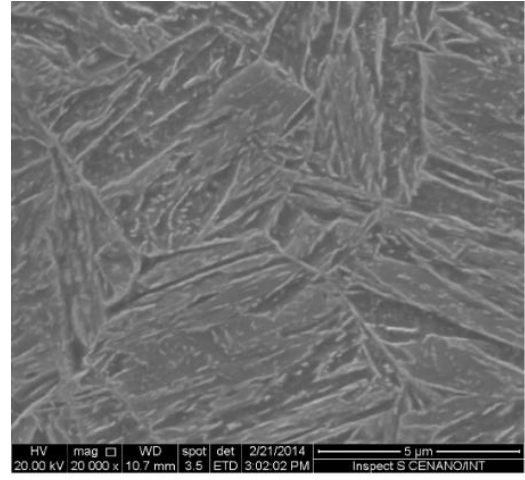

(a)

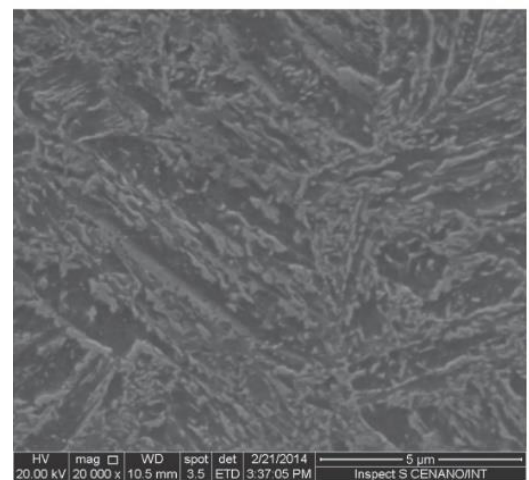

(c)

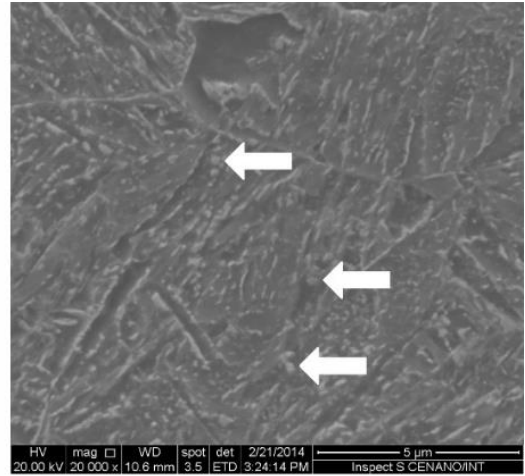

(b)

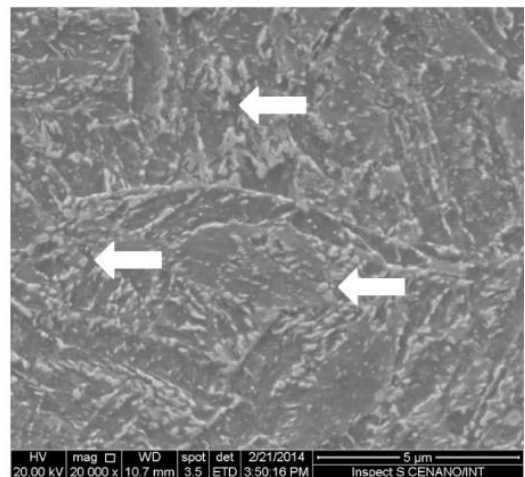

(d)

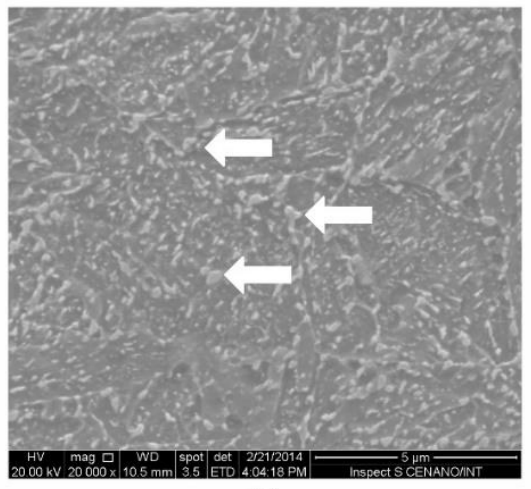

(e)

Figure 6. SEM of tempered samples at: (a) $300^{\circ} \mathrm{C}$, (b) $400^{\circ} \mathrm{C}$, (c) $500^{\circ} \mathrm{C}$, (d) $600^{\circ} \mathrm{C}$ and (e) $650^{\circ} \mathrm{C}$.

Figure 6(a) highlighted a mixed-type martensite microstructure composed of laths and large plates, a feature confirmed by Lee and Su [19], who stated that the medium carbon steels have a complex microstructure. The martensite laths, previously highlighted by optical microscopy, were clear, as well as the contours of previous austenite. At this temperature, the hardness changed little because the fine carbides still provide good strength and counteract the carbon depletion in martensite, which is still small. 
Furthermore, the presence of retained austenite was not detected, although it is more appropriate to characterize the presence of this phase by X-ray or magnetic diffraction measurements. Ajus et al. [20] did not detect the presence of austenite retained in AISI 4340 steel tempered at the same temperature used in this work. This is because the martensite finish temperature, $\mathrm{M}_{\mathrm{f}}$, is above the room temperature and the austenitizing temperature of $860^{\circ} \mathrm{C}$, which is well below the temperature at which retained austenite formation begins.

Figure 6(b) shows a mixed microstructure consisting of laths and some large martensite sheets. As the annealing temperature increased, conditions were more favourable for greater diffusion. Therefore, the carbon in supersaturation in the martensite precipitates in the form of more stable carbides, which have larger dimensions compared to tempering at $300^{\circ} \mathrm{C}$. In this sense, some carbides in the order of $200 \mathrm{~nm}$ were identified by the arrows in Figure 6(b). These particles tended to deplete the matrix in terms of precipitated carbon content, but the hardness remained high because the precipitated carbides were still very fine.

In Figure 6(c), a tempered martensite microstructure was observed and, as well as for the tempering at $400^{\circ} \mathrm{C}$, the precipitated carbides were still very fine. These precipitates hamper the movement of dislocation in the matrix, therefore, the hardness values were still high, but smaller compared to low tempering.

Figure 6(d) showed a tempered martensite microstructure with ferrites and rounded carbides, about the size of $400 \mathrm{~nm}$. In this way, dislocations could move more easily, causing a hardness fall.

Figure 6(e) presented a microstructure similar to Figure 6(d), but with even coarser and rounded carbides $(500 \mathrm{~nm})$, further reducing the hardness shown in Figure 1.

Figure 7 shows the characterization using SEM by secondary electron (SE) and electron backscattered diffraction (EBSD) analysis of fracture surfaces. In some cases, energy dispersive spectroscopy (EDS) was used as an elemental micro-analysis tool to qualitatively determine the chemical composition of certain regions of the fracture surface. 


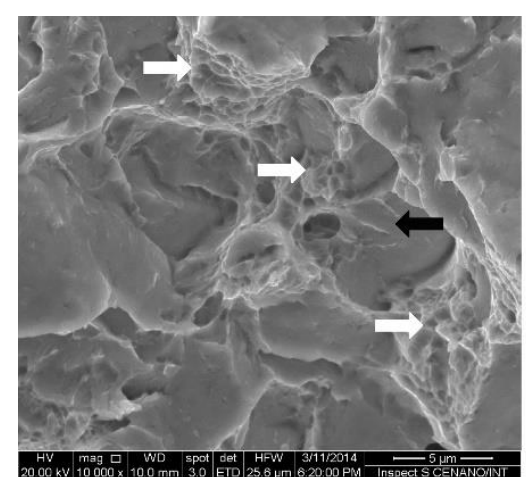

(a)

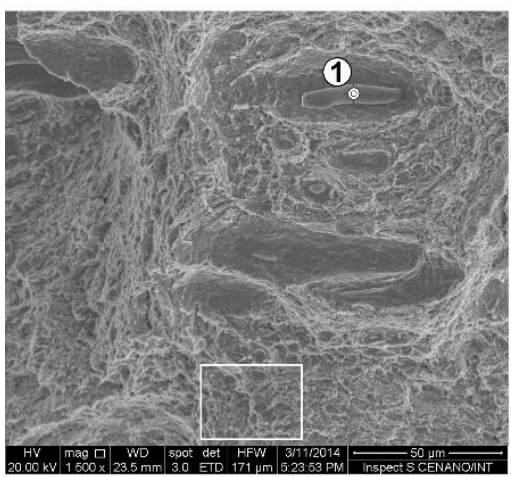

(d)

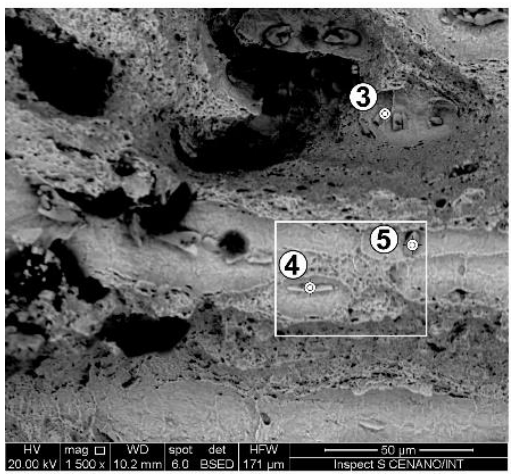

(g)

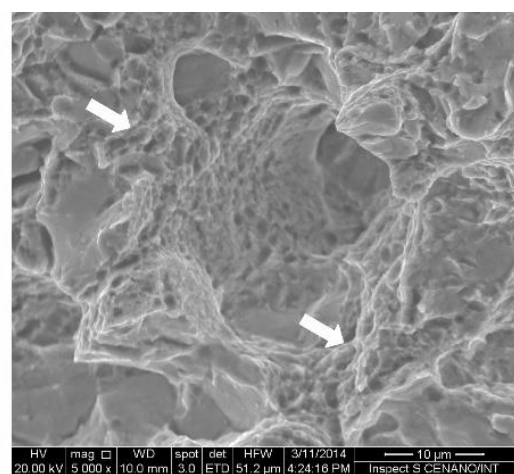

(b)

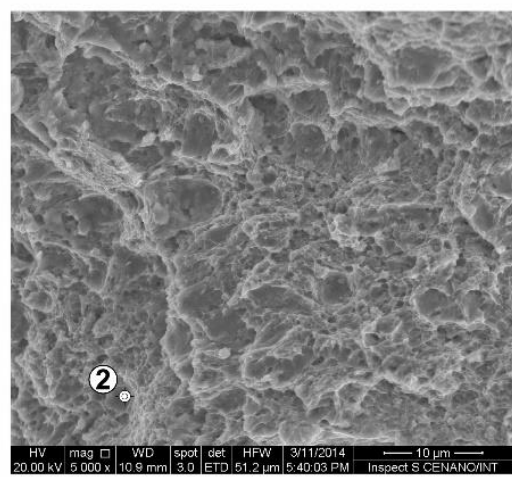

(e)

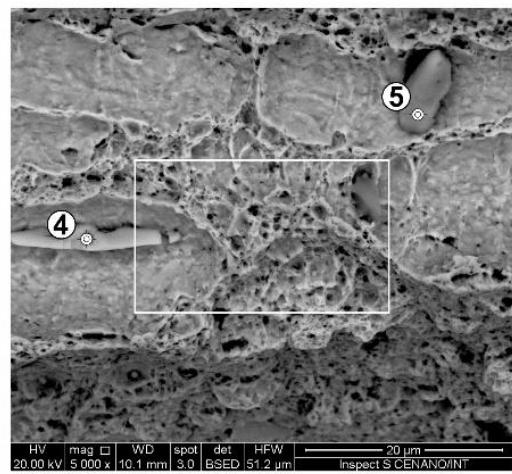

(h)

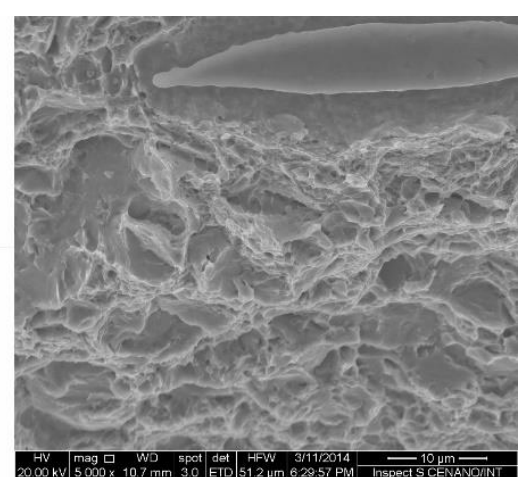

(c)

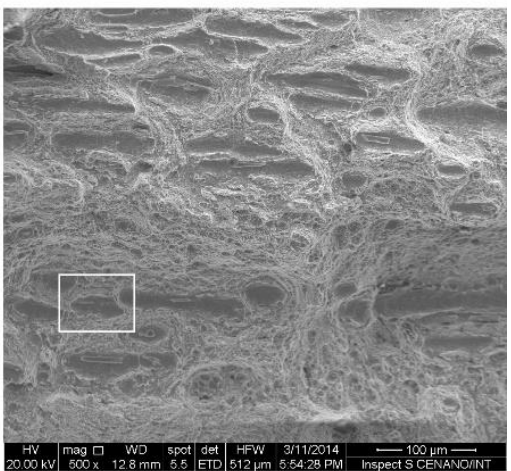

(f)

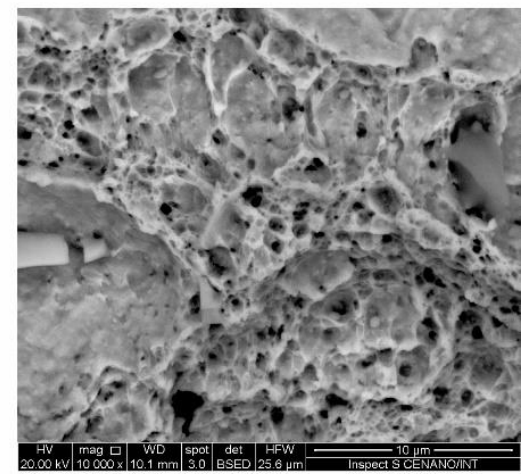

(i)

Figure 7. Fracture surface of tempered samples at: (a) $300^{\circ} \mathrm{C}$, (b) $400^{\circ} \mathrm{C}$, (c) $500^{\circ} \mathrm{C}$, (d) $600^{\circ} \mathrm{C}$, (e) $600^{\circ} \mathrm{C}$ with a selected-area amplification of (d), (f) $650^{\circ} \mathrm{C}$, (g) $650^{\circ} \mathrm{C}$ with a selected-area amplification of (f), (h) $650^{\circ} \mathrm{C}$ with a selected-area amplification of (g), (i) $650^{\circ} \mathrm{C}$ with a selected-area amplification of (h).

Figure 7(a) showed a quasi-cleavage fracture surface and small colonies of dimples or microcavities indicated by the white arrows. A faceted surface was also observed, corresponding to planes of lower atomic density in which the defects have propagated, named as cleavage planes. The dark arrow indicated river patterns, which would correspond to the crack propagation place. 
Figure 7(b) revealed a quasi-cleavage mechanism similar to Figure 7(a), although with smaller microcavities or dimples in a larger proportion.

Figure 7(c) presented elongated inclusions in the direction perpendicular to the notch, having a more fibrous surface appearance than samples tempered at $300^{\circ} \mathrm{C}$ and $400^{\circ} \mathrm{C}$. Thus, the largest proportion and size of dimples were consistent with the absorbed energy for this condition.

Figure 7(d) exhibited inclusions and a more fibrous-looking morphology compared to previous conditions. EDS of point 1 indicated that the inclusion was rich in S and $\mathrm{Mn}$, giving sufficient evidence of this inclusion being a manganese sulfide $(\mathrm{MnS})$, as shown in Table 4. The manufacturer indicated that the material in the as-received condition had $50 \%$ less $\mathrm{S}$ than the maximum allowable by the standard. However, the precise composition of $S$ should be determined by more accurate methodologies, such as combustion, as this element has a significant harmful action in the drop of toughness.

Figure 7(e) showed a fibrous appearance with large sized dimples. An elemental microanalysis was also carried out in point 2 , which corresponded to an inclusion particle that gave rise to a dimple, product of the shear stresses acting on this region. The results shown in Table 4 indicated that the particle was rich in $\mathrm{Mn}$ and $\mathrm{Cr}$.

Table 4. Chemical composition of the points described in Figure 7.

\begin{tabular}{c|c|c|c|c|c|c|c|c}
\hline \multirow{2}{*}{ Point } & \multicolumn{7}{|c}{ Chemical composition (\% weight) } \\
\cline { 2 - 9 } & $\mathrm{Mg}$ & $\mathrm{Al}$ & $\mathrm{S}$ & $\mathrm{Ca}$ & $\mathrm{Mn}$ & $\mathrm{Fe}$ & $\mathrm{Cr}$ & $\mathrm{Ni}$ \\
\hline 1 & 0.00 & 2.01 & 31.80 & 0.43 & 59.33 & 6.44 & 0.00 & 0.00 \\
\hline 2 & 0.00 & 0.02 & 0.03 & 0.11 & 8.29 & 89.87 & 1.68 & 0.00 \\
\hline 3 & 3.61 & 36.04 & 16.37 & 5.52 & 23.94 & 14.52 & 0.00 & 0.00 \\
\hline 4 & 0.00 & 0.00 & 29.92 & 0.72 & 61.00 & 8.36 & 0.00 & 0.00 \\
\hline 5 & 0.00 & 0.00 & 9.85 & 0.42 & 16.33 & 71.38 & 1.05 & 0.98 \\
\hline
\end{tabular}

Figure 7(f) evidenced elongated inclusions in the direction perpendicular to the notch. The fibrous aspect of the fracture was more marked when compared to the sample tempered at $600^{\circ} \mathrm{C}$.

Figure 7(g), (h) and (i), which were amplifications of Figure 7(f), showed dimples colonies. EDS analysis was carried out in points 3, 4 and 5 to characterize the chemical composition of particles and/or inclusions.

Point 3 showed the preponderant presence of $\mathrm{Al}, \mathrm{Mn}, \mathrm{S}, \mathrm{Ca}$ and $\mathrm{Mg}$, highlighting once again the need for strict control of the elements of the studied alloy. 
Point 4 corresponded to an elongated inclusion of $\mathrm{MnS}$ and point 5 was also rich in $\mathrm{Mn}$ and $\mathrm{S}$, noting that, in general, the results were in accordance with what was exposed by Lee and $\mathrm{Su}^{19}$. It is noteworthy that although this type of inclusion is not considered the most damaging in steels in general, the elongated sulfides influence the reduction of impact toughness, since voids are initially formed in the $\mathrm{MnS}$ inclusions during the fracture process.

The arrangement of the sulphides reduced the toughness, since the crack propagation occurred more easily along the grain boundary, clarifying the results below the expected obtained in the impact tests [21].

Additionally, the higher the tempering heat treatment temperature, the greater the amount and size of dimples observed on the fracture surface.

\section{Conclusions}

The present study evaluated the influence of tempering temperature on residual stresses and mechanical properties of AISI 4340 steel and the findings can be summarized as follows:

1- Tempering temperatures above $500^{\circ} \mathrm{C}$ caused a significant residual stresses relief, providing compressive residual stresses in longitudinal and transverse directions.

2- With tempering temperature increase, precipitated carbides become coarser and microstructure, in general, less refined, which explains hardness reduction.

3- The tempering temperature increase caused the decrease of the anchor points of the magnetic domain, facilitating the movement of these domains, thus, producing higher magnetic Barkhausen noise.

4- The mathematical model obtained by regression analysis method allowed predicting the hardness of tempered martensite (HTM) with high accuracy for 1.5 hours holding time.

\section{Declarations}

\section{Acknowledgments}

This study was financed in part by the Coordenação de Aperfeiçoamento de Pessoal de Nível Superior - Brasil (CAPES) - Finance Code 001. The authors would also like to thank the CNPq (304129/2018-6) and FAPERJ (E 26/211.114/2019 (250854) and 03-2017 of Young Scientist of Our State).

Conflict of interest The authors declare that they have no conflict of interest.

Availability of data and material Not applicable. 
Code availability Not applicable.

Ethics approval Not applicable.

Consent to participate Written informed consent for publication was obtained from all participants.

Consent for publication Written informed consent for publication was obtained from all participants.

Authors' contributions Marcel Freitas de Souza: Investigation, Writing - original draft, Writing - review \& editing.

Luana Ferreira Serrão: Conceptualization, Formal analysis, Investigation, Methodology.

Juan Manuel Pardal: Investigation, Methodology, Resources, Supervision, Validation, Writing - original draft.

Sérgio Souto Maior Tavares: Validation, Writing - original draft.

Maria Cindra Fonseca: Conceptualization, Formal analysis, Funding acquisition, Investigation, Methodology, Project administration, Resources, Supervision, Validation, Visualization, Writing - review \& editing.

\section{References}

1. Clarke AJ, Klemm-Toole J, Clarke KD et al (2020) Perspectives on Quenching and Tempering 4340 Steel. Metall Mater Trans A 51:4985-5005. https://doi.org/10.1007/s11661020-05972-1

2. Kwon H, Cha JC, Kim CH (1988) The effect of grain size on fracture behavior in tempered martensite embrittlement for AISI 4340 steel. Mater Sci Eng 100:121-128. https://doi.org/10.1016/0025-5416(88)90247-9

3. Chi YC, Lee S, Cho K, Duffy J (1989) The effects of tempering and test temperature on the dynamic fracture initiation behavior of an AISI 4340 VAR steel. Mater Sci Eng A 114:105-126. https://doi.org/10.1016/0921-5093(89)90850-2

4. Kashefi M, Rafsanjani A, Kahrobaee S, Alaee M (2012) Magnetic nondestructive technology for detection of tempered martensite embrittlement. J Magn Magn Mater 324:4090-4093. https://doi.org/10.1016/j.jmmm.2012.07.029 
5. Davut K, Gür CH (2007) Monitoring the microstructural changes during tempering of quenched SAE 5140 steel by Magnetic Barkhausen Noise. J Nondestr Eval 26:107-113. https://doi.org/10.1007/s10921-007-0025-X

6. Moorthy V, Shaw BA, Evans JT (2003) Evaluation of tempering induced changes in the hardness profile of case carburized EN36 steel using magnetic Barkhausen noise analysis. NDT \& E Int 36(1):43-49. https://doi.org/10.1016/S0963-8695(02)00070-1

7. Santa-aho S, Sorsa A, Honkanen M, Vippola M (2020) Detailed Barkhausen noise and microscopy characterization of Jominy end-quench test sample of CF53 steel. J Mater Sci 55:4896-4909. https://doi.org/10.1007/s10853-019-04284-z

8. Jiang B, Wu M, Zhang M, Zhao F, Zhao Z, Liu Y (2017) Microstructural characterization, strengthening and toughening mechanisms of a quenched and tempered steel: Effect of heat treatment parameters. Mater Sci Eng A 707:306-314. https://doi.org/10.1016/j.msea.2017.09.062

9. ASM Handbook Volume 4A (2013) Steel Heat Treating Fundamentals and Processes. ASM International, Materials Park

10. Manokaran M, Kashinath AS, Jha JS, Toppo SP, Singh RP (2020) Influence of Tempering in Different Melting Routes on Toughness Behavior of AISI 4340 Steel. J Mater Eng Perform 29(10):6748-6760. https://doi.org/10.1007/s11665-020-05164-3

11. Ning D, Dai CR, Wu JL, Wang YD, Wang YQ, Jing Y, Sun J (2021) Carbide precipitation and coarsening kinetics in low carbon and low alloy steel during quenching and subsequently tempering. Mater Charact 176: 111111. https://doi.org/10.1016/j.matchar.2021.111111

12. García Navas V, Ferreres I, Marañón JA, Garcia-Rosales C, Sevillano JG (2008) Electro-discharge machining (EDM) versus hard turning and grinding - Comparison of residual stresses and surface integrity generated in AISI O1 tool steel. J Mater Process Technol 195(13):186-194. https://doi.org/10.1016/j.jmatprotec.2007.04.131

13. Withers PJ, Bhadeshia HKDH (2001) Residual stress. Part 1 - Measurement techniques. Mater Sci Technol 17:355-365.

14. Hassan AD, Jabbar MA (2021) New Prediction Model of Tempered Martensite Hardnesses for Quenched and Tempered Low-Alloy Steel. Mater Perform Charact 10(1):267-277. https://doi.org/10.1520/MPC20200104

15. Hollomon JH, Jaffe LD (1945) Time-Temperature Relations in Tempering Steel. Trans Metall Soc AIME 162:223-249. 
16. Kang S, Lee S (2014) Prediction of Tempered Martensite Hardness Incorporating the Composition-Dependent Tempering Parameter in Low Alloy Steels. Mater Trans 55(7):10691072. https://doi.org/10.2320/matertrans.M2014004

17. ASTM E140 (2019) Standard Hardness Conversion Tables for Metals Relationship Among Brinell Hardness, Vickers Hardness, Rockwell Hardness, Superficial Hardness, Knoop Hardness, Scleroscope Hardness, and Leeb Hardness. https://doi.org/10.1520/E014012BR19E01

18. Thompson S (2018) Further Observations of Linear Arrays of Transition-Iron-Carbide Precipitates in Tempered 4340 Steel. Metall Microstruct Anal 7:680-691. https://doi.org/10.1007/s13632-018-0492-8

19. Lee W, Su T (1999) Mechanical properties and microstructural features of AISI 4340 high-strength alloy steel under quenched and tempered conditions. J Mater Process Technol 87(1-3):198-206. https://doi.org/10.1016/S0924-0136(98)00351-3

20. Ajus C, Tavares SSM, Silva MR, Corte RRA (2009) Magnetic properties and retained austenite quantification in SAE 4340 steel. Revista Matéria 14(3):993-999. https://doi.org/10.1590/S1517-70762009000300011

21. Tavares SSM, Pardal JM, Souza JA, Pereira OC, Luz TS (2016) Failure of alloy steel socket-head cap screws used in offshore oil production. Eng Fail Anal 70:16-21. https://doi.org/10.1016/j.engfailanal.2016.07.004 
Table 1. Chemical composition of AISI 4340 (\% weight).

\begin{tabular}{c|c|c|c|c|c|c|c|c|c|c}
\hline & $\mathrm{C}$ & $\mathrm{Mn}$ & $\mathrm{Si}$ & $\begin{array}{c}\mathrm{P} \\
(\max )\end{array}$ & $\begin{array}{c}\mathrm{S} \\
(\max )\end{array}$ & $\mathrm{Cr}$ & $\mathrm{Ni}$ & $\mathrm{Mo}$ & $\mathrm{Al}$ & $\mathrm{Cu}$ \\
\hline Manufacturer & 0.40 & 0.73 & 0.28 & 0.01 & 0.02 & 0.78 & 1.73 & 0.21 & 0.02 & 0.11 \\
\hline \multirow{2}{*}{ SAE 4340 } & $\begin{array}{c}0.38 \\
-\end{array}$ & $\begin{array}{c}0.60 \\
-\end{array}$ & $\begin{array}{c}0.15 \\
-\end{array}$ & 0.04 & 0.04 & $\begin{array}{c}0.70 \\
-\end{array}$ & $\begin{array}{c}1.65 \\
-\end{array}$ & $\begin{array}{c}0.20 \\
-\end{array}$ & - & - \\
\hline
\end{tabular}


Table 2. Mechanical properties of AISI 4340.

\begin{tabular}{c|c|c|c|c}
\hline$\sigma_{\text {YS }}(\mathrm{MPa})$ & $\sigma_{\text {UTS }}(\mathrm{MPa})$ & Elongation $(\%)$ & RA $(\%)$ & Rockwell Hardness (HRC) \\
\hline 765 & 960 & 14.8 & 39.5 & 32 \\
\hline
\end{tabular}


Table 3. Equation parameters for alloying effect according to Kang and Lee [16].

\begin{tabular}{l|c|c|c|c|c|c|c}
\hline Parameter & $H_{0}$ & $H_{C}$ & $H_{M n}$ & $H_{S i}$ & $H_{N i}$ & $H_{C r}$ & $H_{M o}$ \\
\hline Value & 17.396 & -6.661 & -1.604 & -3.412 & -0.248 & -1.112 & -4.355 \\
\hline
\end{tabular}


Table 4. Chemical composition of the points described in Figure 7.

\begin{tabular}{c|c|c|c|c|c|c|c|c}
\hline \multirow{2}{*}{ Point } & \multicolumn{8}{|c}{ Chemical composition (\% weight) } \\
\cline { 2 - 9 } & $\mathrm{Mg}$ & $\mathrm{Al}$ & $\mathrm{S}$ & $\mathrm{Ca}$ & $\mathrm{Mn}$ & $\mathrm{Fe}$ & $\mathrm{Cr}$ & $\mathrm{Ni}$ \\
\hline 1 & 0.00 & 2.01 & 31.80 & 0.43 & 59.33 & 6.44 & 0.00 & 0.00 \\
\hline 2 & 0.00 & 0.02 & 0.03 & 0.11 & 8.29 & 89.87 & 1.68 & 0.00 \\
\hline 3 & 3.61 & 36.04 & 16.37 & 5.52 & 23.94 & 14.52 & 0.00 & 0.00 \\
\hline 4 & 0.00 & 0.00 & 29.92 & 0.72 & 61.00 & 8.36 & 0.00 & 0.00 \\
\hline 5 & 0.00 & 0.00 & 9.85 & 0.42 & 16.33 & 71.38 & 1.05 & 0.98 \\
\hline
\end{tabular}




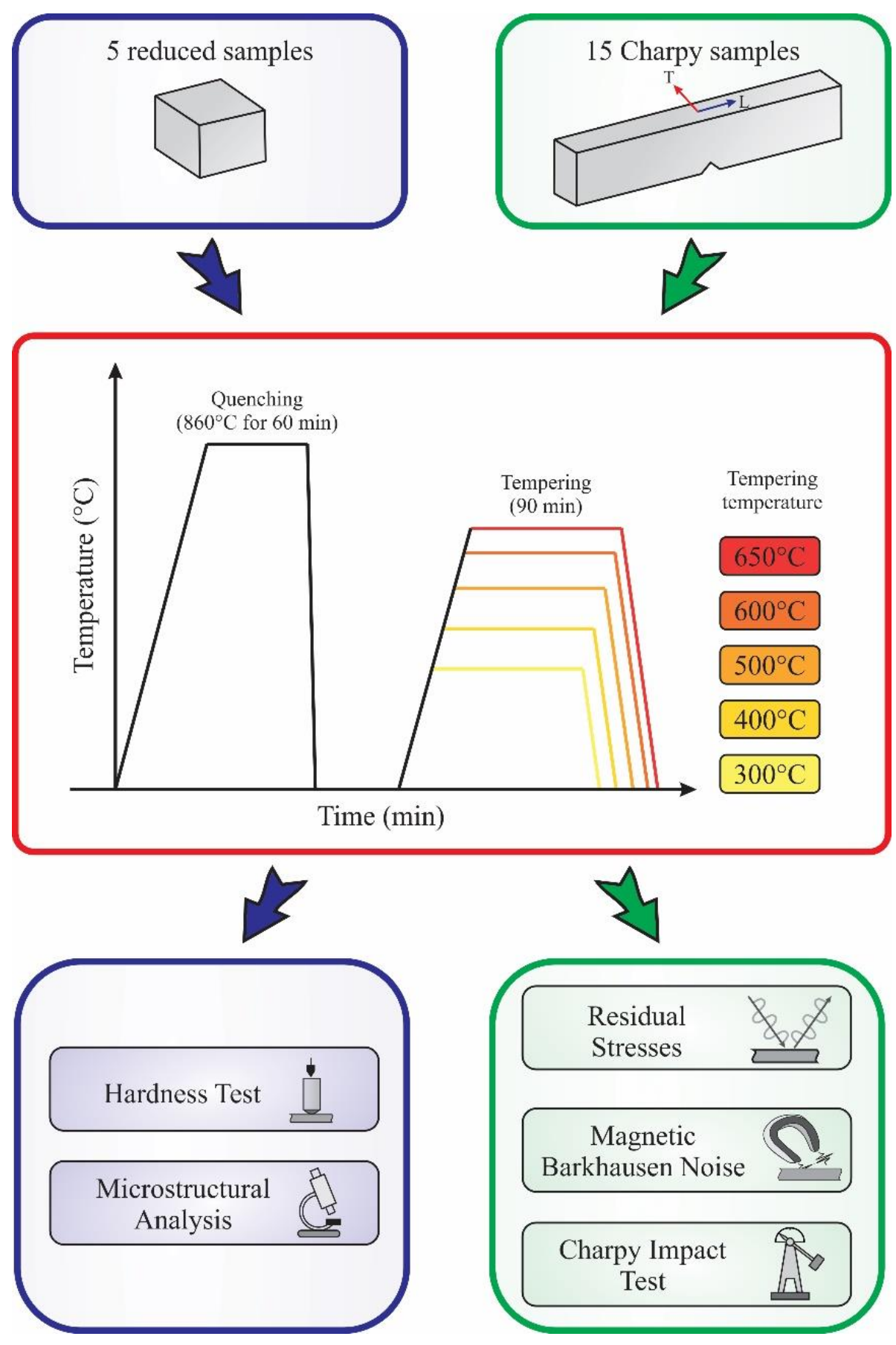

Figure 1. Flowchart with heat treatment parameters and tests performed in this experiment. 


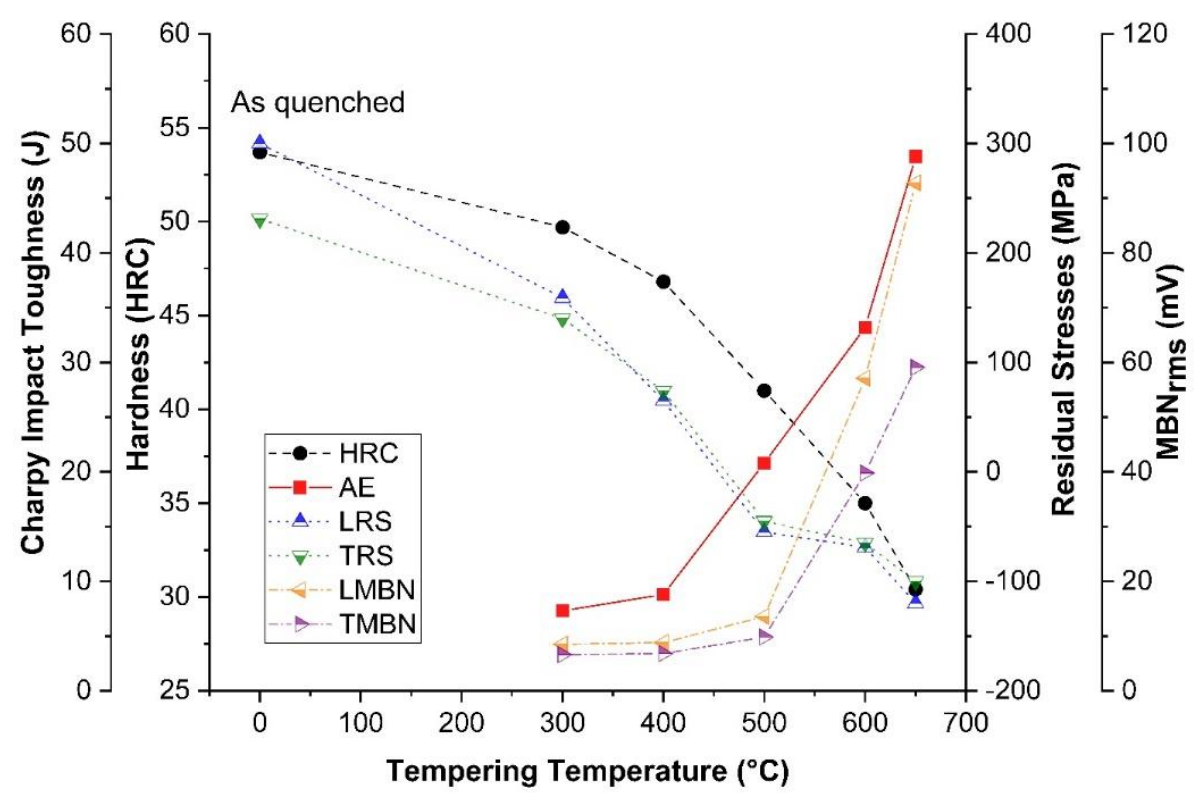

Figure 2. Mechanical properties, residual stresses and MBN vs. tempering temperature. 


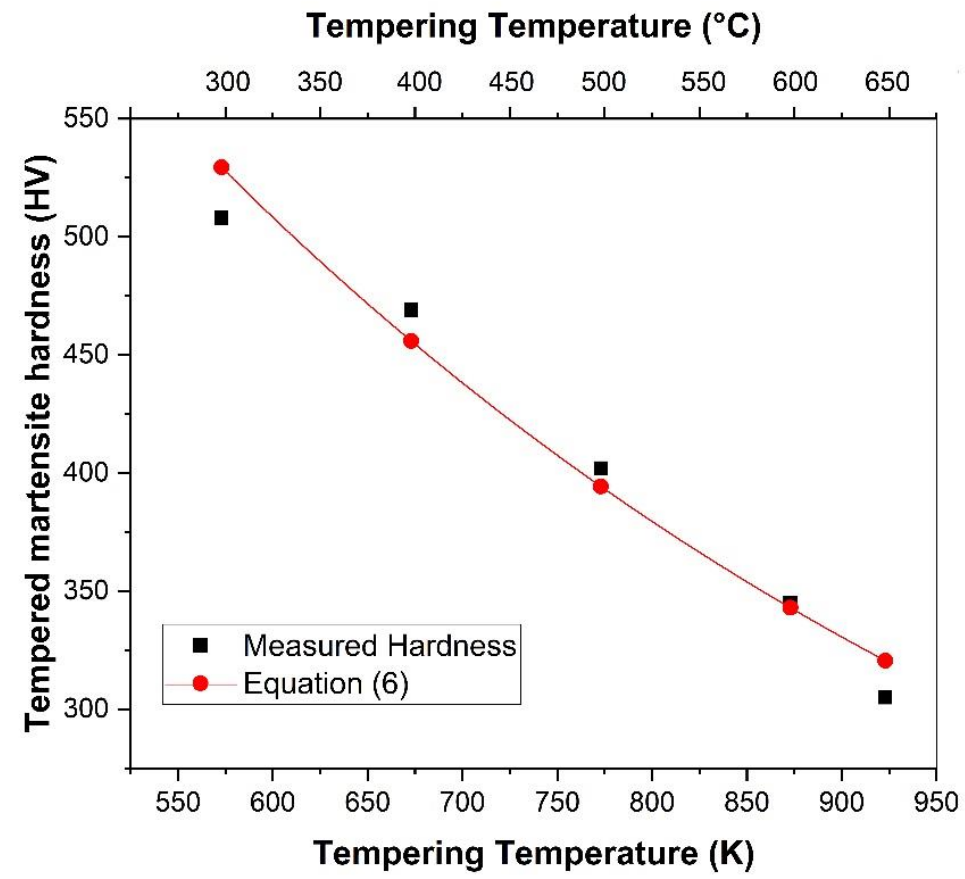

Figure 3. Variation of measured and calculated hardness for a holding time of $1.5 \mathrm{~h}$. 


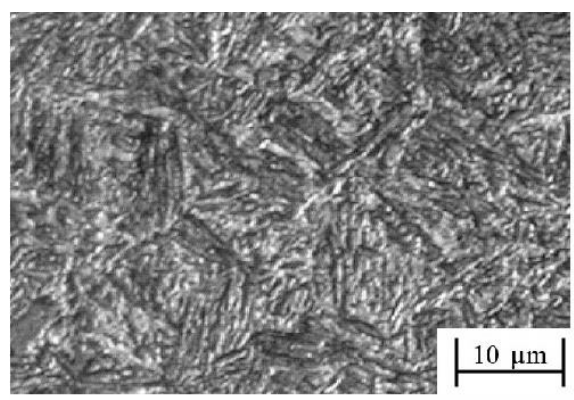

(a)

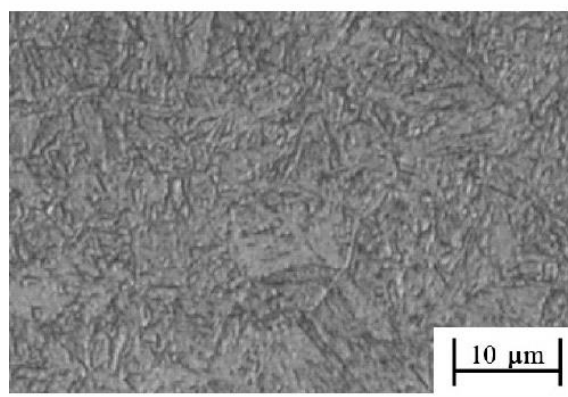

(c)

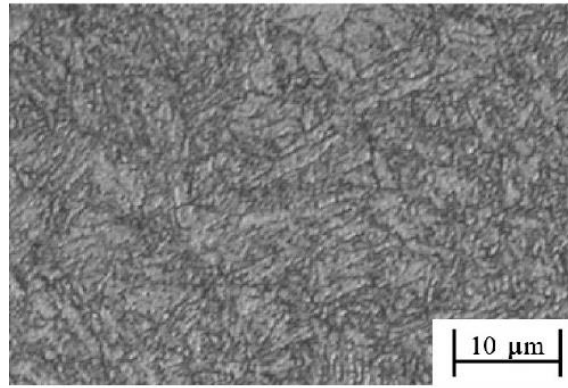

(e)

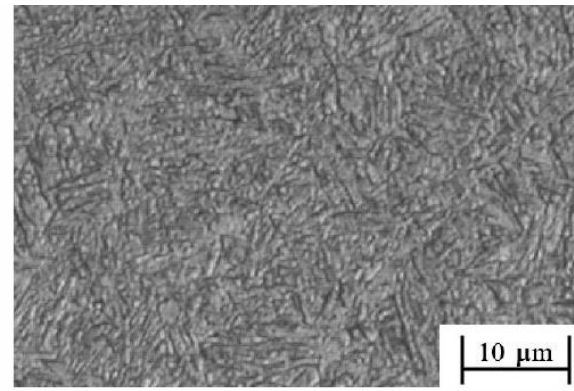

(b)

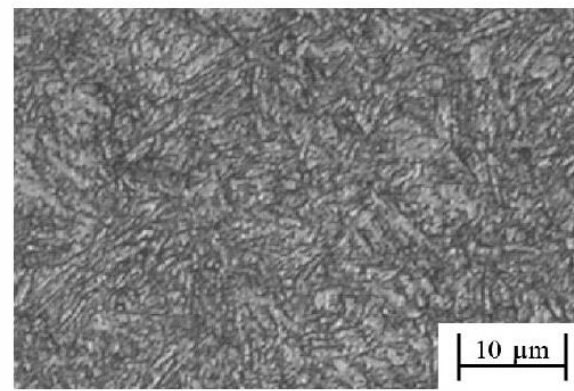

(d)

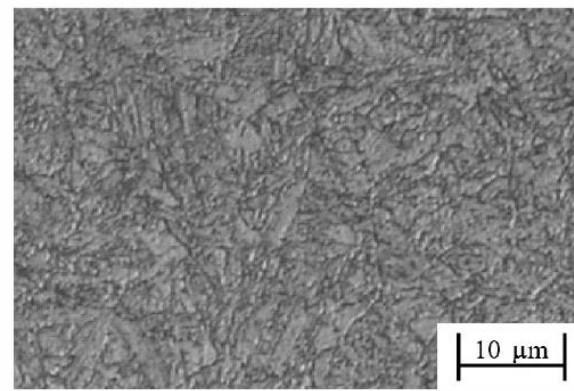

(f)

Figure 4. (a) Microstructure after quenching. Microstructure of tempered sample at: (b) $300^{\circ} \mathrm{C}$, (c) $400^{\circ} \mathrm{C}$, (d) $500^{\circ} \mathrm{C}$, (e) $600^{\circ} \mathrm{C}$ and (f) $650^{\circ} \mathrm{C}$. 


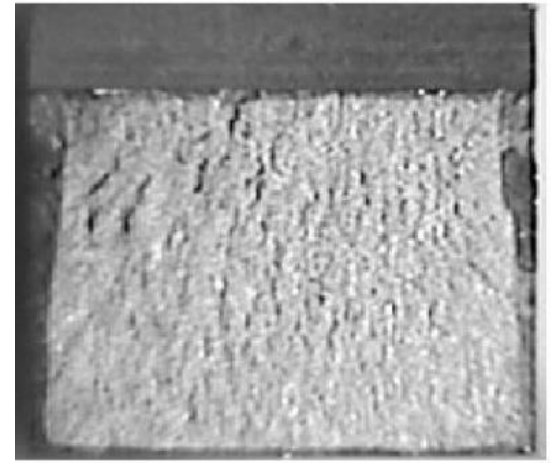

(a)

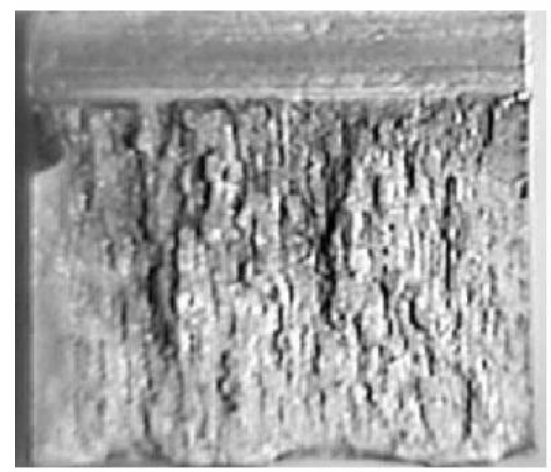

(c)

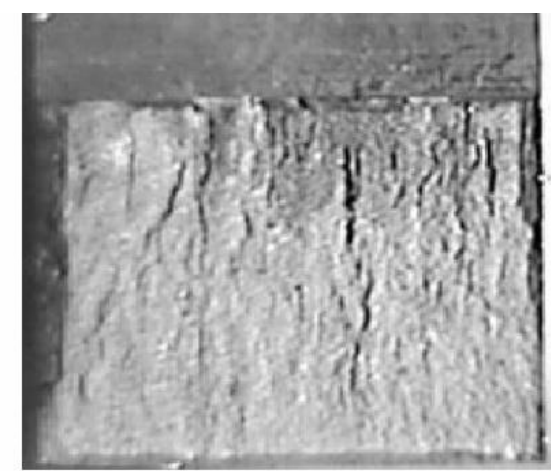

(b)

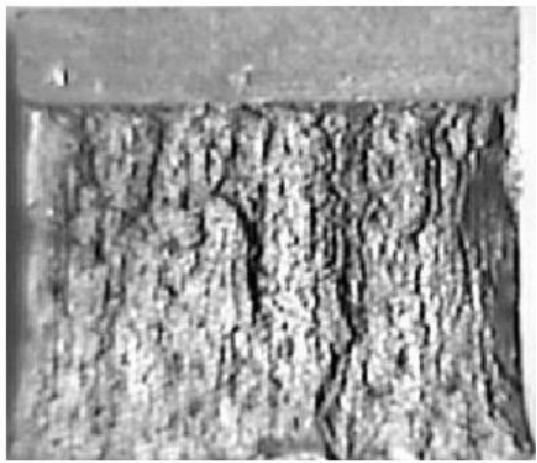

(d)

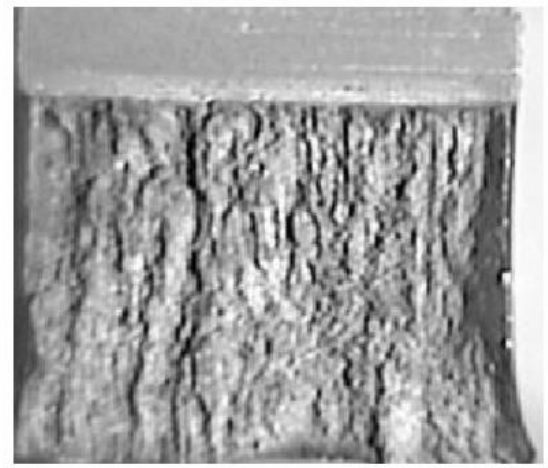

(e)

Figure 5. Fracture surfaces of tempered sample at: (a) $300^{\circ} \mathrm{C}$, (b) $400^{\circ} \mathrm{C}$, (c) $500^{\circ} \mathrm{C}$, (d) $600^{\circ} \mathrm{C}$ and (e) $650^{\circ} \mathrm{C}$. 


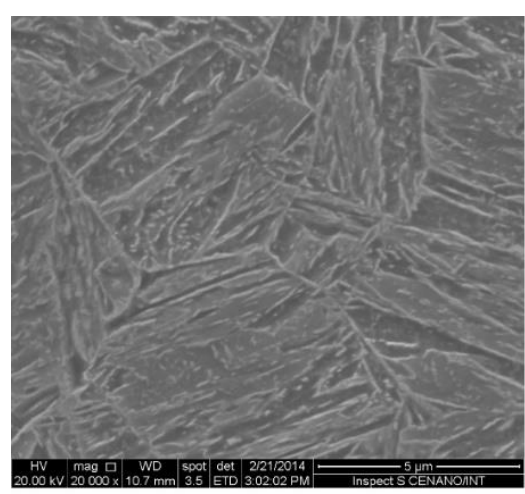

(a)

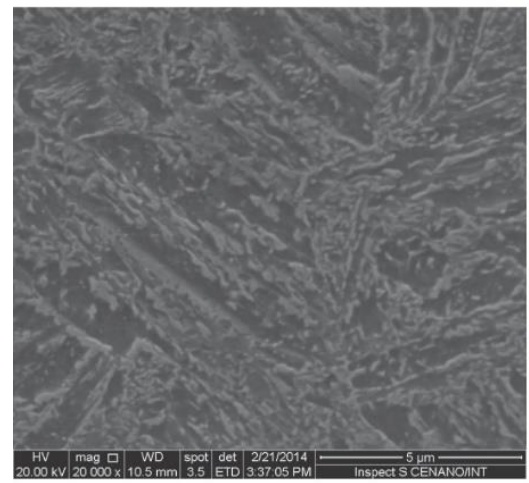

(c)

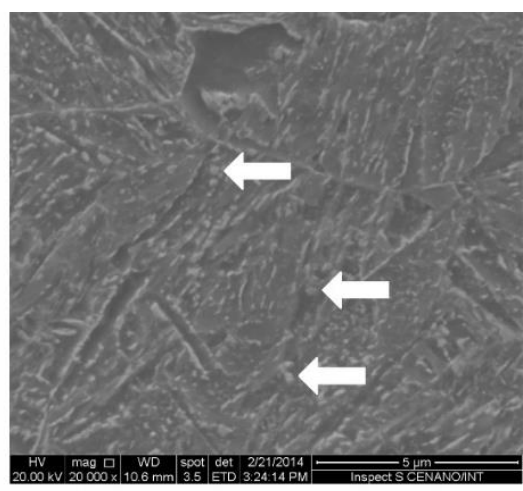

(b)

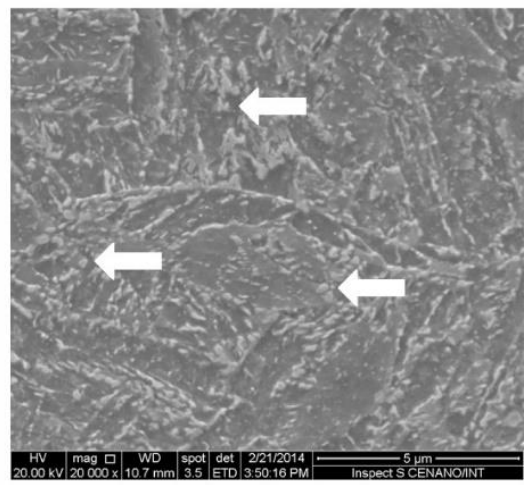

(d)

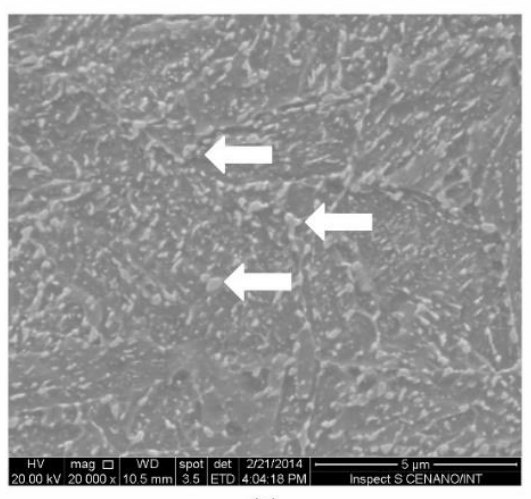

(e)

Figure 6. SEM of tempered samples at: (a) $300^{\circ} \mathrm{C}$, (b) $400^{\circ} \mathrm{C}$, (c) $500^{\circ} \mathrm{C}$, (d) $600^{\circ} \mathrm{C}$ and (e) $650^{\circ} \mathrm{C}$. 


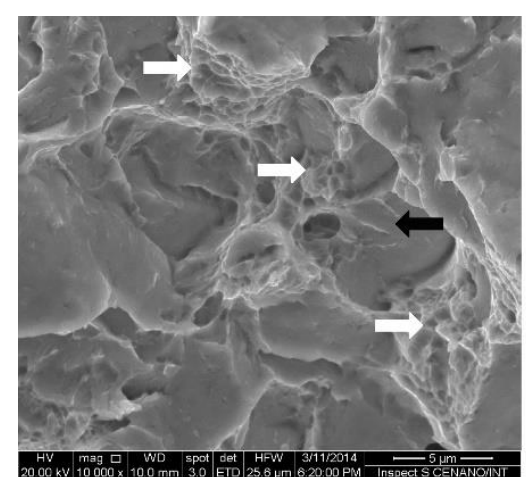

(a)

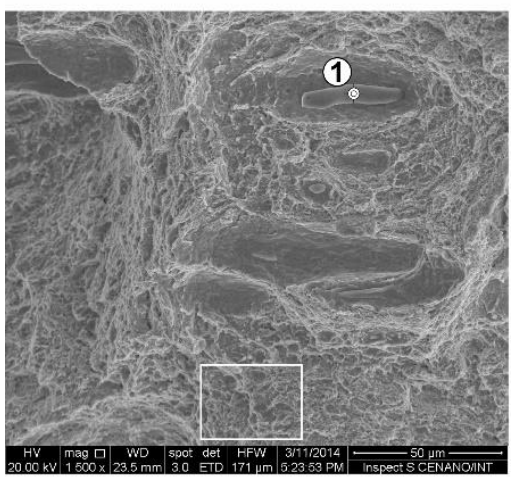

(d)

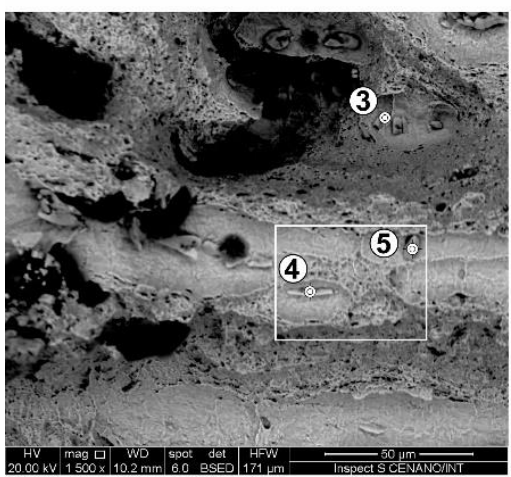

(g)

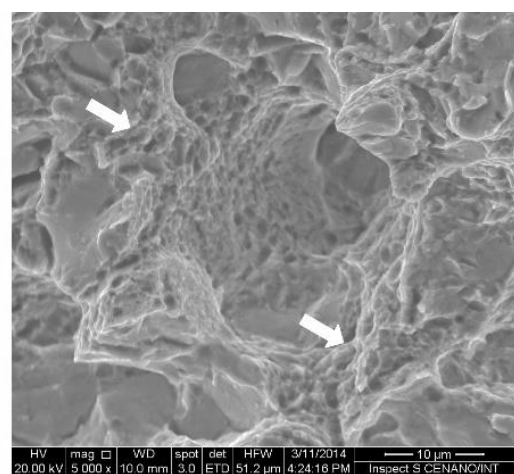

(b)

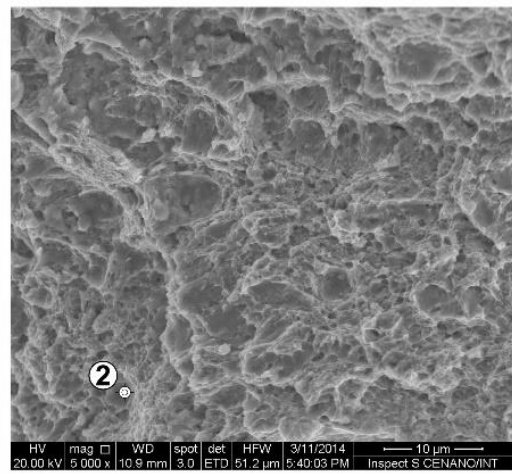

(e)

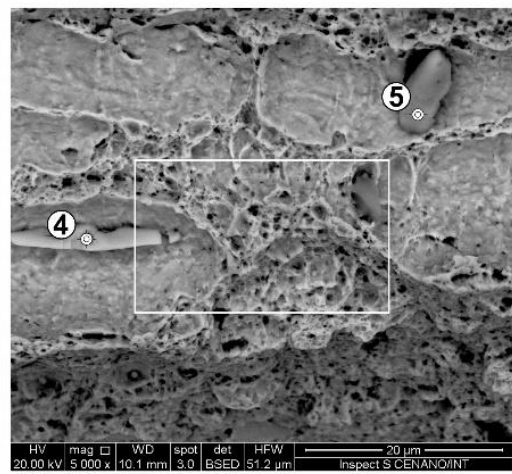

(h)

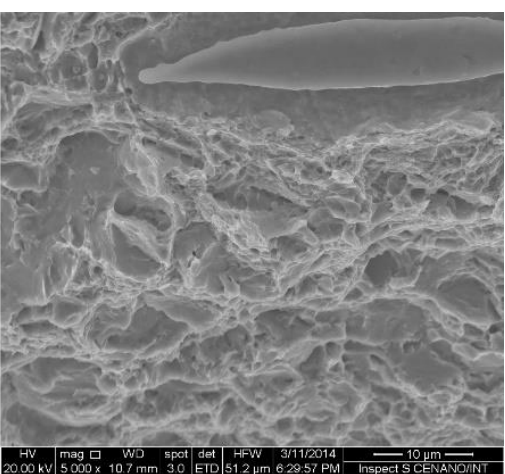

(c)

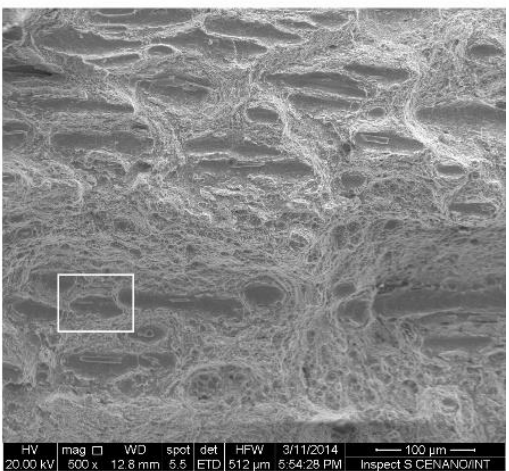

(f)

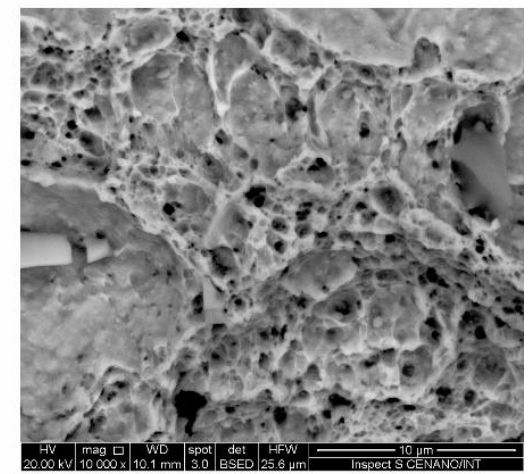

(i)

Figure 7. Fracture surface of tempered samples at: (a) $300^{\circ} \mathrm{C}$, (b) $400^{\circ} \mathrm{C}$, (c) $500^{\circ} \mathrm{C}$, (d) $600^{\circ} \mathrm{C}$, (e) $600^{\circ} \mathrm{C}$ with a selected-area amplification of (d), (f) $650^{\circ} \mathrm{C},(\mathrm{g}) 650^{\circ} \mathrm{C}$ with a selected-area amplification of (f), (h) $650^{\circ} \mathrm{C}$ with a selected-area amplification of (g), (i) $650^{\circ} \mathrm{C}$ with a selected-area amplification of (h). 


\section{Figure captions}

Figure 1. Flowchart with heat treatment parameters and tests performed in this experiment.

Figure 2. Mechanical properties, residual stresses and MBN vs. tempering temperature.

Figure 3. Variation of measured and calculated hardness for a holding time of $1.5 \mathrm{~h}$.

Figure 4. (a) Microstructure after quenching. Microstructure of tempered sample at: (b) $300^{\circ} \mathrm{C}$, (c) $400^{\circ} \mathrm{C}$, (d) $500^{\circ} \mathrm{C}$, (e) $600^{\circ} \mathrm{C}$ and (f) $650^{\circ} \mathrm{C}$.

Figure 5. Fracture surfaces of tempered sample at: (a) $300^{\circ} \mathrm{C}$, (b) $400^{\circ} \mathrm{C}$, (c) $500^{\circ} \mathrm{C}$, (d) $600^{\circ} \mathrm{C}$ and (e) $650^{\circ} \mathrm{C}$.

Figure 6. SEM of tempered samples at: (a) $300^{\circ} \mathrm{C}$, (b) $400^{\circ} \mathrm{C}$, (c) $500^{\circ} \mathrm{C}$, (d) $600^{\circ} \mathrm{C}$ and (e) $650^{\circ} \mathrm{C}$.

Figure 7. Fracture surface of tempered samples at: (a) $300^{\circ} \mathrm{C}$, (b) $400^{\circ} \mathrm{C}$, (c) $500^{\circ} \mathrm{C}$, (d) $600^{\circ} \mathrm{C}$, (e) $600^{\circ} \mathrm{C}$ with a selected-area amplification of (d), (f) $650^{\circ} \mathrm{C},(\mathrm{g}) 650^{\circ} \mathrm{C}$ with a selected-area amplification of (f), (h) $650^{\circ} \mathrm{C}$ with a selected-area amplification of (g), (i) $650^{\circ} \mathrm{C}$ with a selected-area amplification of (h). 